\title{
El Código Orgánico General de Procesos: puente u obstáculo para la ejecución de un laudo arbitral extranjero en el Ecuador ${ }^{*}$
}

\author{
María del Carmen Crespo** \\ Recibido/Received: 11/01/2016 \\ Aceptado/Accepted: 19/08/2016
}

SUMARIO: 1. Introducción y planteamiento del problema. 2. Puntualizaciones conceptuales relacionadas con un laudo extranjero. 3. Normativa vigente en el Ecuador para el reconocimiento y ejecución de un laudo arbitral extranjero. 3.1 Constitución de la República del Ecuador. 3.2 Tratados y convenios internacionales 3.3 Leyes orgánicas. 3.4 Leyes ordinarias. 4. Coherencia normativa entre la Convención de Nueva York, la Ley de Arbitraje y Mediación y el Código Orgánico General de Procesos. 4.1 Interacción normativa. 4.2 Resolución de antinomias. 5. Conclusiones.

PALABRAS CLAVE: Ejecución, Reconocimiento Laudo extranjero, Convención de Nueva York, Código Orgánico General de Procesos, conflicto de normas.

KEYWORDS: Enforcement, Recognition of foreign arbitral awards, New York Convention, General Procedure Organic Code, conflict of laws.

* Las ideas presentadas en este artículo son reflexiones realizadas desde una perspectiva abstracta y con un enfoque puramente académico. Todas las direcciones de páginas de internet citadas han sido visitadas por última vez el 10/01/2016.

** Reportera para International Arbitration Case Law, Coordinadora Regional de AMCHAM YAP, Mediadora. Abogada por la Universidad del Azuay, Especialista Superior en Derecho Ambiental Internacional por la Universidad de Berkeley-California, Magíster de Investigación en Derecho con mención Derecho Tributario por la Universidad Andina Simón Bolívar, Sede Ecuador.

M. CRespo, "El Código Orgánico General de Procesos: puente u obstáculo para la ejecución de un laudo arbitral extranjero en el Ecuador", Revista Ecuatoriana de Arbitraje, No. 7, 2015. 
RESUMEN: El reconocimiento y ejecución de laudos extranjeros implica la coordinación entre normas de carácter internacional y local. En el Ecuador históricamente el procedimiento de homologación y ejecución no ha estado esclarecido en el derecho local y las recientes reformas al sistema procesal parecen haber complicado aún más el panorama. Si bien el Ecuador es suscriptor de la Convención de Nueva York y esta debe surtir efecto como parte del sistema jurídico nacional, hay contradicciones de orden constitucional y legal que parecerían alterar sus disposiciones. En este marco de conflicto normativo, la aplicación técnica de los métodos de resolución de antinomias parecerían favorecer la vigencia de la Convención de Nueva York. Sin embargo de este análisis, no hay aún constatación práctica de casos que pueda generar precedentes jurisprudenciales esclarecedores.

ABSTRACT: Recognition and enforcement of foreign awards involves coordination between international and local laws. In Ecuador, historically the recognition and execution procedure has not been clarified in local law and recent reforms to the general rules of civil procedure seem to have further complicated the picture. While Ecuador is a signatory of the New York Convention and it should have effect as part of the national legal system, there are contradictions of constitutional and legal order that would seem to alter its provisions. In this conflicted regulatory framework, technical implementation of the resolution methods for antinomies should favor the validity of the New York Convention. Notwithstanding this analysis, there is still a lack of practical cases that can generate enlightening precedent.

\section{INTRODUCCIÓN Y PLANTEAMIENTO DEL PROBLEMA}

Viajar y traspasar fronteras pueden ser catalogadas como las actividades más placenteras para la mayoría de personas, mien- 
tras que para otras puede resultar todo un dolor de cabeza. Independientemente del grado de satisfacción que esta actividad pueda producir; a consecuencia de la globalización, el emprender viajes es una actividad cada vez más común, y hay cosas básicas que todo viajero debe saber antes de partir. Lo primero será conocer el destino y los requisitos de ingreso a ese país, posteriormente habrá que escoger el medio de transporte más adecuado, y por último, pero no menos importante, no olvidar la maleta y el dinero que se va a necesitar.

En la actualidad y gracias al desarrollo de los negocios internacionales, no solamente son las personas quienes traspasan fronteras y deben cumplir con los requisitos exigidos por el país de destino, sino también lo son ciertos instrumentos como los laudos extranjeros. Generalmente un proceso arbitral concluye con la emisión de este documento, y se espera que lo resuelto por los árbitros sea cumplido voluntariamente por las partes, sin embargo, en el caso de que esto no suceda, es necesario recurrir a cortes nacionales para exigir aquel cumplimiento.

Con relación a laudos nacionales se debe solicitar su ejecución ante las cortes del lugar en el que fue sede del arbitraje, sin que exista mayores problemas al respecto. No obstante esto no es tan simple con laudos emitidos en el extranjero, y es cuando el viaje se puede volver tormentoso. Por la propia naturaleza del arbitraje internacional, en casi todos sus casos la sede arbitral no coincide con los países en los que el demandante ni el demandado residen, hecho que genera ciertas interrogantes acerca del procedimiento de ejecución de un laudo internacional. Frente a las dudas que pueden seguir, a nivel internacional existen tratados y convenios que pretenden establecer parámetros de uniformidad aplicables para el procedimiento mencionado.

Para el presente viaje el destino es el Ecuador, país en donde para muchos "los requisitos de ingreso" más que dolores de cabeza, han causado jaquecas. Esto se debe a que el Estado Ecuatoriano, si bien, ha ratificado diversos instrumentos internacionales 
El Código Orgánico General de Procesos:

puente u obstáculo para la ejecución de un laudo arbitral extranjero en el Ecuador

relacionados a la materia, cuenta con una ley especial que rige para temas arbitrales y recientemente se promulgó el Código Orgánico General de Procesos (COGEP), en el que se incluyó un capítulo relacionado con sentencias, laudos arbitrales y actas de mediación expedidos en el extranjero.

En este contexto, previo a que el viajero defina su medio de transporte y lo que incluirá en su maleta, al revisar todo lo que debe cumplir y dónde hacerlo, puede verse tentado a cambiar de destino. Empero, antes de negarse a apreciar las maravillas del Ecuador y sus normas, resulta necesario analizar precisamente si existe coherencia entre las varias normas locales que inciden en el reconocimiento y ejecución de un laudo extranjero, su pertinencia y respectiva aplicación. En el marco teórico que nos permitirá realizar ese análisis, y responder si el Código Orgánico General de Procesos es un puente o un obstáculo para la ejecución de un laudo extranjero en el Ecuador, se realizarán [2] puntualizaciones conceptuales relacionadas con un laudo extranjero; luego se analizará la [3] normativa vigente en el Ecuador para el reconocimiento y ejecución de un laudo arbitral extranjero; y en base a las mismas, se concretará acerca de la [4] coherencia normativa entre la Convención de Nueva York, la Ley de Arbitraje y Mediación y el Código Orgánico General de Procesos.

\section{Puntualizaciones Conceptuales Relacionadas CON UN LAUDO EXTRANJERO}

El procedimiento arbitral puede terminar por varios motivos, pero básicamente existen dos posibilidades. La una es denominada normal, cuando un árbitro resuelve la controversia mediante la emisión de un laudo, y la otra es por terminación anormal, en la que por diversos hechos el árbitro no emite un criterio que ponga fin al conflicto ${ }^{1}$. El laudo arbitral es un acto decisorio que resuelve una controversia, debe estar motivado y

1. J. F. Merino Merchán, y J. M. Chillón Medina, Tratado de Derecho Arbitral, 3ra. Ed., Thomson Civitas, 2006, p. 645. 
cumplir con ciertas formalidades; según el profesor SALCEDO VERDUGA, "tanto por su contenido formal como por el sustancial, el laudo equivale a una verdadera sentencia y, por esta razón, su alcance y efectos son idénticos ${ }^{2 \prime \prime}$. Acertadamente el autor hace referencia solo a los efectos, ya que si bien entre las principales características del laudo es que tiene fuerza de cosa juzgada formal y material, y su ejecución solamente puede ser ordenada por jueces, en su naturaleza jurídica, los dos no son iguales.

De igual manera en razón de la naturaleza del arbitraje internacional, resulta imprescindible distinguir el origen del laudo para determinar su procedimiento de ejecución. Por esta razón "la diferenciación entre arbitraje nacional e internacional es muy importante, ya que se rigen por normas distintas; mientras el primero se rige por la legislación interna de un Estado, el segundo está regulado principalmente por instrumentos internacionales de derecho privado" ${ }^{\prime 3}$.

La Ley de Arbitraje y Mediación ${ }^{4}$ asume una posición mixta al adoptar la mayoría de elementos que la Ley Modelo sobre Arbitraje Comercial Internacional de la CNUDMI exige para que un arbitraje se considere internacional. Algunos elementos comunes entre los dos cuerpos normativos a tomarse en consideración son: el lugar de cumplimiento de una parte sustancial de las obligaciones o el lugar en el cual el objeto del litigio tenga relación con un determinado estado. Por otro lado, cuando la sede del arbitraje esté localizada fuera del Ecuador, es decir en un país extranjero (independientemente de cualquier otro factor de conexión), este arbitraje será considerado como un arbitraje extranjero, ya que conforme la ley que regula la materia, la sede del tribunal arbitral y el laudo tienen lugar fuera del territorio nacional ${ }^{5}$.

2. E. SAlcedo Verguda, El arbitraje, la justicia alternativa, Distrilib, 2007, p. 257.

3. X. Andrade CAdena, "Las Ventajas del Arbitraje Internacional: Una Perspectiva Ecuatoriana", Revista de Derecho Comparado, No. 11, 2005.

4. Ley de Arbitraje y Mediación (LAM), Artículo 41, RO No. 147, 14/12/2006.

5. Para efectos del presente estudio se utilizará la clasificación de arbitraje nacional e internacional, incluyendo dentro de este último a un arbitraje extranjero y se utilizará la denominación laudo extranjero, a pesar de las peculiaridades de cada uno de ellos ya que su análisis profundo nos alejaría del objeto de este trabajo. 
El Código Orgánico General de Procesos:

puente u obstáculo para la ejecución de un laudo arbitral extranjero en el Ecuador

Si bien se acepta de manera general que "las resoluciones que no sean dictadas en el territorio del país en donde se pretende tengan vigor, [...] no gozan inicialmente de la misma eficacia que las proferidas por los tribunales nacionales ${ }^{6 \prime \prime}$; en el supuesto de existir un instrumento internacional aplicable para un caso en particular, se debe estar a lo dispuesto ese instrumento. Al ser el contenido del mismo ratificado por el Estado, se demuestra la voluntad estatal de cumplirlo, pudiendo en ciertas ocasiones, aceptarse la ejecución directa de una resolución internacional obviando el procedimiento de reconocimiento. Lo dicho tiene lógica en razón de que la fuente más certera y confiable del derecho internacional está constituida por los tratados, y por ello, las cortes se ven abocadas a cumplirlos.

Para la ejecución de laudos extranjeros, el instrumento multilateral que ha sido ratificado por la mayoría de países del mundo es la Convención de las Naciones Unidas sobre el Reconocimiento y Ejecución de Sentencias Arbitrales Extranjeras de $1958^{7}$. Este tratado internacional establece la obligación a los Estados suscriptores de reconocer y ejecutar un laudo emitido fuera de su territorio, y resulta relevante debido a que su irradiación lo convierte en un cuerpo normativo universal para el arbitraje internacional ${ }^{8}$. Si bien la Convención hace referencia al reconocimiento y ejecución de sentencias extranjeras, estos términos no son sinónimos. El reconocimiento "[...] es el proceso que vuelve a los laudos arbitrales parte del sistema legal nacional ${ }^{9 "}$, y "la ejecución de un laudo es el acto judicial, obligatorio y forzoso por el cual un juez hace efectiva la decisión de los árbitros sobre la materia controvertida, utilizando para ello todas las medidas que la legislación contemple $\mathrm{e}^{10 \prime}$.

6. V. Aguirre, "La ejecución de los laudos internacionales en Ecuador y el Código Orgánico General de Procesos", Revista Ecuatoriana de Arbitraje, No. 6, 2014, p. 83.

7. Convención de las Naciones Unidas sobre el Reconocimiento y Ejecución de Sentencias Arbitrales Extranjeras (Convención de Nueva York/Convención) (1961), RO No. 43, 29/12/1961.

8. J. F. Merino Merchán, J. M. Chillón Medina, N. 1, p. 1801.

9. International Council for Commercial Arbitration, "Guía del ICCA para la interpretación de la Convención de Nueva York de 1958: un manual para jueces”, International Council for Commercial Arbitration, 2013, p. 9.

10. X. Andrade CADENa, "Reconocimiento y Ejecución de Laudos Extranjeros en el Ecuador: Un Camino Inexplorado" $<\mathrm{http}: / /$ goo.gl/EEO1v4> (10/01/16). 
De manera global, dentro del ordenamiento jurídico ecuatoriano los principales instrumentos normativos relacionados con el tema analizado son la Convención Interamericana sobre Arbitraje Comercial Internacional ${ }^{11}$; la Convención Interamericana sobre Eficacia Extraterritorial de las Sentencias y Laudos Arbitrales Extranjeros ${ }^{12}$; la Convención de las Naciones Unidas sobre el Reconocimiento y Ejecución de Sentencias Arbitrales Extranjeras; la Ley de Arbitraje y Mediación ${ }^{13}$-LAM- y el Código Orgánico General de Procesos ${ }^{14}$. Previa a la promulgación del COGEP, el Código de Procedimiento Civil debía contener las normas supletorias aplicables para la ejecución de un laudo extranjero, sin embargo, a consecuencia de la deficiente regulación del tema se generaron más interrogantes que respuestas.

De acuerdo con lo establecido por varios autores, no es posible definir el derecho considerando aisladamente a la norma, por lo que es necesario ampliar el horizonte para tomar en consideración el modo por el cual existe una organización que determina su eficacia, las sanciones, las personas que deben aplicarlas y la ejecución; organización que es el resultado de un ordenamiento jurídico ${ }^{15}$. Al existir dentro de nuestro sistema varias normas relacionadas con el procedimiento aplicable al reconocimiento y ejecución de un lado extranjero, no se puede aislar a un solo cuerpo normativo para entenderlo; por lo que será necesario analizar todas las normas relevantes en el ordenamiento jurídico ecuatoriano y así determinar su coherencia.

11. RO No. $875,14 / 02 / 1992$.

12. RO No. $240,11 / 05 / 1982$.

13. RO No. 417, 14/12/2006.

14. Código Orgánico General de Procesos (COGEP), RO Sup. No. 506, 22/05/2015.

15. Norberto BobBio, Teoría General del Derecho, Temis, 1999, p. 143. 
El Código Orgánico General de Procesos:

puente u obstáculo para la ejecución de un laudo arbitral extranjero en el Ecuador

\section{Normativa Vigente en El ECUAdor PARA EL RECONOCIMIENTO Y EJECUCIÓN DE UN LAUDO ARBITRAL EXTRANJERO}

El sistema jurídico ecuatoriano se encuentra estructurado de manera general conforme a lo establecido por Hans KelsEN. Según el mencionado autor el sistema jurídico "no es un conjunto de normas vigentes, unas al lado de otras, sino una pirámide o jerarquía de normas supremas o subordinadas unas a otras, superiores o inferiores"16. Para el autor existe una norma fundamental, que es "el punto de partida del procedimiento de creación positiva del derecho"17.

En el contexto ecuatoriano, la norma fundamental es la Constitución de la República del Ecuador, ya que se establece que esta es la norma suprema y que prevalecerá sobre cualquier otra norma del ordenamiento jurídico ${ }^{18}$. Con relación a la jerarquía normativa, la Constitución determina expresamente que el orden jerárquico de aplicación de las normas será el siguiente: la Constitución, los tratados y convenios internacionales, las leyes orgánicas, las leyes ordinarias, las normas regionales y las ordenanzas distritales, los decretos y reglamentos, las ordenanzas, los acuerdos y las resoluciones, y los demás actos y decisiones de los poderes públicos ${ }^{19}$.

A partir de esta jerarquización constitucional, se analizarán las normas relacionadas con el reconocimiento y la ejecución de un laudo extranjero en el Ecuador hasta el nivel de las leyes. En la etapa de análisis de los tratados internacionales solamente se profundizará acerca de la Convención de Nueva York, al ser el instrumento internacional más importante de la materia y constituir la base de las otras dos convenciones previamente mencionadas.

16. H. Kelsen, Théorie Pure du Droit, 1963, citado por F. Ost; M.VAn DER KerChOVE. Elementos para una Teoría Crítica del Derecho, Universidad Nacional de Colombia, 2001, p. 117.

17. F. Ost; M.VAn der Kerchove, N. 11.

18. Constitución de la República del Ecuador, Artículo 424, RO No. 449, 20/10/2008.

19. Ídem, Artículo 425. 


\subsection{Constitución de la República del Ecuador}

En el artículo 190 se reconoce al arbitraje como un método válido para la solución de controversias, disponiendo que sus procedimientos se aplicarán con sujeción a la ley. Posteriormente en el artículo 422 se establece una prohibición de celebrar tratados o instrumentos internacionales en los que el Estado Ecuatoriano ceda jurisdicción soberana a instancias de arbitraje internacional, en controversias contractuales o de índole comercial, entre el Estado y personas naturales o jurídicas privadas. Se exceptúan los tratados e instrumentos internacionales que establezcan la solución de controversias entre Estados y ciudadanos en Latinoamérica por instancias arbitrales regionales o por órganos jurisdiccionales de designación de los países signatarios.

Independientemente de ciertas premisas jurídicas, que a criterio de varios autores son incorrectas ${ }^{20}$, en el presente trabajo se enfocará solamente la limitación que tiene el Estado de participar en arbitrajes internacionales, contractuales o comerciales; la cual no es absoluta y tiene dos excepciones marcadas. La primera que se encuentra desarrollada en la misma norma, ya que acepta arbitrajes regionales producto de un tratado o instrumento internacional entre Estados y ciudadanos en Latinoamérica; y la segunda, que se deduce de la prohibición de participar en arbitrajes internacionales de índole comercial, dejando abierta la posibilidad de participar en otro tipo de arbitrajes internacionales, como los que surgen de la violación de un tratado internacional de inversiones. En estos dos casos también se genera la obligación del Estado de reconocer un laudo extranjero resultado de estos procesos arbitrales internacionales.

20. Véase un análisis a profundidad del artículo 422 de J. M. MARCHÁN, El tratamiento del arbitraje en la nueva Constitución ecuatoriana, disponible en <http://goo.gl/Iaxjre> (10/01/2016). 
El Código Orgánico General de Procesos:

puente u obstáculo para la ejecución de un laudo arbitral extranjero en el Ecuador

\subsection{Tratados y convenios internacionales}

\section{Convención de las Naciones Unidas sobre el Reconocimiento y Ejecución de Sentencias Arbitrales Extranjeras}

El Ecuador suscribió la Convención de Nueva York bajo reservas; por esta razón el Estado solo la aplicará para el reconocimiento y la ejecución de laudos extranjeros bajo el principio de reciprocidad ${ }^{21}$ y a controversias derivadas de relaciones jurídicas, sean o no contractuales, consideradas como comerciales por su derecho interno ${ }^{22}$. Al ser un tratado internacional, forma parte del Derecho Internacional Público, por lo que su interpretación se la debe realizar conforme reglas establecidas en los artículos 31 y 32 de la Convención de Viena sobre el Derecho de los Tratados.

El objetivo principal de la Convención es "evitar que las sentencias arbitrales, tanto extranjeras como no nacionales, sean objeto de discriminación, por lo que obliga a los Estados parte a velar por que dichas sentencias sean reconocidas en su jurisdicción y puedan ejecutarse en ella, en general, de la misma manera que las sentencias o laudos arbitrales nacionales. ${ }^{23 "}$ Para cumplir con su objetivo, la misma consta de dieciséis artículos, que entre los principales se establece que:

Art. III.- Cada uno de los Estados contratantes reconocerá la autoridad de la sentencia arbitral y concederá su ejecución de conformidad con las normas de procedimiento vigentes en el territorio donde la sentencia sea invocada, con arreglo a las condiciones que se establecen en los artículos siguientes. Para el reconocimiento o la ejecución de las sentencias arbitrales a que se aplica la presente Convención, no se impondrán condiciones apreciablemente más rigurosas, ni honorarios o costas más elevados,

21. Solamente se aplicará para laudos dictados en el territorio de otro Estado Contratante.

22. A pesar de que no existe una definición clara para el término comercial, las cortes deben de interpretar la noción de comercialidad de manera amplia. International Council for Commercial Arbitration, N. 9 , p. 25.

23. Convención sobre el Reconocimiento y la Ejecución de las Sentencias Arbitrales Extranjeras (2015), disponible en $<$ http://goo.gl/g9Fsti>, (10/01/2016). 
que los aplicables al reconocimiento o a la ejecución de las sentencias arbitrales nacionales. (Énfasis agregado)

Con la demanda en la que se solicita el reconocimiento y ejecución de un laudo extranjero, la parte solicitante debe adjuntar: a) El original debidamente autenticado de la sentencia o una copia de ese original que reúna las condiciones requeridas para su autenticidad, y b) El original del acuerdo a que se refiere el artículo II, o una copia que reúna las condiciones requeridas para su autenticidad. En el caso de que el acuerdo o sentencia arbitral no estuvieran en el idioma oficial del país en que se invoca el reconocimiento y la ejecución, la parte que lo solicita deberá presentar una traducción certificada a ese idioma ${ }^{24}$.

En el artículo V se establecen las únicas causales por las que se podrá denegar el reconocimiento y la ejecución del laudo arbitral, y la parte contra quien se lo invoca, deberá probar:

a) Que las partes en el acuerdo a que se refiere el artículo II estaban sujetas a alguna incapacidad en virtud de la ley que le es aplicable o que dicho acuerdo no es válido en virtud de la ley a que las partes lo han sometido, o si nada se hubiera indicado a este respecto, en virtud de la ley del país en que se haya dictado la sentencia;

b) Que la parte contra la cual se invoca la sentencia arbitral no ha sido debidamente notificada de la designación del árbitro o del procedimiento de arbitraje o no ha podido, por cualquier otra razón, hacer valer sus medios de defensa;

c) Que la sentencia se refiere a una diferencia no prevista en el compromiso o no comprendida en las disposiciones de la cláusula compromisoria, o contiene decisiones que exceden de los términos del compromiso o de la cláusula compromisoria; no obstante, si las disposiciones de la sentencia que se refieren a las cuestiones sometidas al arbitraje pueden separarse de las que no han sido sometidas al arbitraje, se podrá dar reconocimiento y ejecución a las primeras;

24. Convención de Nueva York (1961), Art. 6(1), N. 7. 
El Código Orgánico General de Procesos:

puente u obstáculo para la ejecución de un laudo arbitral extranjero en el Ecuador

d) Que la constitución del tribunal arbitral o el procedimiento arbitral no se han ajustado al acuerdo celebrado entre las partes o, en defecto de tal acuerdo, que la constitución del tribunal arbitral o el procedimiento arbitral no se han ajustado a la ley del país donde se ha efectuado el arbitraje;

e) Que la sentencia no es aún obligatoria para las partes o ha sido anulada o suspendida por una autoridad competente del país en que, o conforme a cuya ley, ha sido dictada esa sentencia.

Bajo estos postulados, las condiciones de ejecución son solamente las establecidas por la Convención de Nueva York, y ningún Estado podrá imponer condiciones más rigurosas. Es necesario tener presente que la Convención le exige al solicitante solamente presentar el laudo y el acuerdo arbitral debidamente autentificados. Cumplidos esos requisitos, el demandado podrá oponerse únicamente en base a las causales mencionadas. La Convención no establece nada acerca de asuntos procesales distintos a las reglas sobre la carga de la prueba y a los documentos que deben de ser presentados por la parte solicitante, por lo que surge una relación de complementariedad entre la ley nacional y la Convención; en donde el procedimiento se regirá por normas nacionales pero respetará los aspectos desarrollados en el instrumento internacional.

\subsection{Leyes orgánicas}

\section{Código Orgánico General de Procesos}

El Código Orgánico General de Procesos, modificó el artículo 42 de la LAM y creó un capítulo destinado a sentencias, laudos arbitrales y actas de mediación expedidos en el extranjero. En el artículo 102 determina que el reconocimiento y homologación de laudos arbitrales con efecto de sentencia en la legislación de origen, expedidos en el extranjero, corresponderá a la sala de la Corte Provincial especializada del domicilio del requerido. Pos- 
teriormente la ejecución le corresponderá al juzgador de primer nivel del domicilio de la persona demandada, quien será competente en razón de la materia ${ }^{25}$.

Con relación a los efectos de las sentencias, laudos arbitrales y actas de mediación expedidos en el extranjero, el artículo 103 menciona que los que hayan sido homologados y que hayan sido pronunciados en procesos contenciosos o no contenciosos tendrán en el Ecuador la fuerza que les concedan los tratados y convenios internacionales vigentes, sin que proceda su revisión sobre el asunto de fondo ${ }^{26}$. Para la homologación, el artículo 104 establece que la sala competente de la Corte Provincial deberá verificar:

1. Que tengan las formalidades externas necesarias para ser considerados auténticos en el Estado de origen.

2. Que la sentencia pasó en autoridad de cosa juzgada conforme con las leyes del país en donde fue dictada y la documentación anexa necesaria está debidamente legalizada.

3. Que de ser el caso, estén traducidos.

4. Que se acredite con las piezas procesales y certificaciones pertinentes que la parte demandada fue legalmente notificada y que se haya asegurado la debida defensa de las partes.

5. Que la solicitud indique el lugar de citación de la persona natural o jurídica contra quien se quiere hacer valer la resolución expedida en el extranjero.

Independiente de la pertinencia que puedan tener o no los artículos mencionados, en el desarrollo de todo el Capítulo VII se incurre en ciertas impresiones. La primera es asimilar a las sentencias y a las actas de mediación con un laudo extranjero. Si bien el laudo tiene efecto de sentencia ejecutoriado y cosa juzgada, ninguno de los tres instrumentos son iguales y su tratamiento no debe ser el mismo. El origen de cada uno es distinto y se rige por distinta normativa, por lo que los requisitos y el procedimiento de homologación debería respetar las peculiaridades de cada pro-

25. COGEP, Artículo 102, RO Sup. No. 506, 22/05/2015.

26. Ídem, Art. 103. 
cedimiento. La segunda imprecisión se relaciona con la competencia, por un lado de la sala especializada de la Corte Provincial para conocer la homologación, a su vez asignando a los juzgadores de primer nivel aquella respecto de la ejecución; la norma hace referencia a la materia, sin embargo, la competencia arbitral ratioe materia se refiere a cuestiones transigibles, por lo que surge la interrogante acerca de cuál es la sala o el juzgado que debería ser competente para conocer esas solicitudes.

Con relación a los requisitos que la Corte Provincial debe verificar, el primero, el tercero y el quinto no implican mayores complicaciones; sin embargo, no ocurre lo mismo con el segundo y el cuarto. El segundo requisito exige que el laudo debe haber pasado en autoridad de cosa juzgada conforme con las leyes del país en donde fue dictado y adjuntar la documentación debidamente legalizada; y la imposibilidad de ejecutar en el Ecuador laudos que no sean finales, como son los laudos parciales, o de jurisdicción.

En lo referente con el cuarto requisito, el solicitante debe probar que se haya asegurado la debida defensa de las partes, es decir, tanto del actor como del demandado, e impone la carga de esa prueba al solicitante. En palabras de los autores GALINDO y GARCÍA:

Además de imponer la carga de la prueba al solicitante esta disposición generaría una carga extremadamente gravosa, por varios motivos. Primero, qué derechos comprenden el derecho a la defensa de una parte, ¿aquellos comprendidos en la legislación de la sede?, ¿aquellos enunciados en la constitución del Ecuador? Segundo, ciertos derechos son virtualmente imposibles de probar pues solo se evidencian cuando son vulnerados. Tercero, este requisito parecería imponer al solicitante la prueba de un hecho negativo -que no se haya vulnerado el derecho a la debida defensa de la contraparte$\mathrm{y}$, ciertamente, es jurídicamente imposible probar un hecho negativo ${ }^{27}$.

27. A. Galindo y H. García, "Relación entre el Código Orgánico General de Procesos y el procedimiento arbitral", Revista Ecuatoriana de Arbitraje, No. 6. 2014, p. 77. 
En relación al procedimiento de homologación, se reconoce la posibilidad de que la persona demandada se oponga, pero no se mencionan las causales de oposición, por lo que de conformidad con la Convención de Nueva York, solo podrá oponerse si se prueban una de las causales del artículo $\mathrm{V}^{28}$.

\subsection{Leyes ordinarias}

\section{Ley de Arbitraje y Mediación}

Su artículo 32 menciona que ejecutoriado el laudo, las partes deberán cumplirlo de inmediato. Cualquiera de las partes podrá pedir a los jueces ordinarios, que ordenen la ejecución del laudo presentando una copia certificada del laudo o acta transaccional, otorgada por el secretario del tribunal, el director del centro o del árbitro o árbitros, respectivamente con la razón de estar ejecutoriada. El laudo se ejecutará del mismo modo que las sentencias de última instancia, y seguirán la vía de apremio.

Con relación al arbitraje internacional, previa a la reforma realizada mediante la disposición derogatoria decimotercera del COGEP, el artículo 42 de la LAM establecía que los laudos dictados dentro de un procedimiento de arbitraje internacional tendrían los mismos efectos, y serían ejecutados de la misma forma, que los laudos dictados en un procedimiento de arbitraje nacional. Este artículo incitó a un largo debate en el foro ecuatoriano. La discusión giraba en torno a la obligatoriedad o no de solicitar el reconocimiento del laudo extranjero previo a su ejecución; ya que se defendía la tesis que conforme al artículo previamente citado y en relación al artículo 37 de la LAM; de forma supletoria se aplicaba el Código de Procedimiento Civil, y se solicitaba directamente la ejecución.

28. La Convención de Nueva York, utiliza la palabra "podrá" por lo que a pesar de que se pruebe la existencia de la causal, la decisión final es facultativa para el juez del lugar ante quien se solicita el reconocimiento y la ejecución. 
Ahora el artículo 42 dispone que el arbitraje internacional quedará regulado por los tratados, convenciones, protocolos y demás actos de derecho internacional suscritos y ratificados por el Ecuador; que toda persona natural o jurídica, pública o privada, sin restricción alguna es libre de estipular directamente o mediante referencia a un reglamento de arbitraje todo lo concerniente al procedimiento arbitral, incluyendo la constitución, la tramitación, el idioma, la legislación aplicable, la jurisdicción y la sede del tribunal, la cual podrá estar en el Ecuador o en país extranjero. Para que el Estado o las instituciones del sector público puedan someterse al arbitraje internacional se estará a lo dispuesto en la Constitución y leyes de la República.

\section{Coherencia normativa entre la Convención de Nueva York, La Ley de Arbitraje y Mediación Y el Código Orgánico General de Procesos}

Lo ideal de todo sistema jurídico es que en el mismo no existan lagunas normativas y por consiguiente sea pleno ${ }^{29}$. No solamente se debe hacer referencia a si un supuesto de hecho en un determinado sistema es calificado como obligatorio, prohibido o permitido, sino que también se debe analizar la coherencia que existe entre las normas que lo regulan. La coherencia normativa es "aquella cualidad del sistema en cuya virtud cada situación de hecho recibe un único tratamiento normativo dentro del sistema en cuestión ${ }^{30 \prime}$. Lo contrario es denominado como antinomia y se produce cuando "un mismo comportamiento es calificado deónticamente de modo incompatible por dos o más normas del sistema o, lo que viene a ser lo mismo, siempre que a un mismo supuesto se imputan dos o más consecuencias incompatibles ${ }^{31 "}$.

Con relación al reconocimiento de un laudo arbitral extranjero, previo al procedimiento de ejecución en el Ecuador, la Con-

29. L. Prieto Sanchís, Apuntes De Teoría Del Derecho, Trotta, 2005, p. 123.

30. Ídem, p. 131.

31. Ibídem. 
vención de Nueva York, la Ley de Arbitraje y Mediación y el Código Orgánico General de Procesos, contienen normas que se relacionan directamente con el tema y todas se encuentran vigentes dentro del ordenamiento jurídico ecuatoriano. Considerando que existe coincidencia en el ámbito de validez material, temporal y espacial de las normas analizadas previamente (al ser normas que establecen reglas para un mismo supuesto), se presentaría una contradicción normativa. Sin embargo, para confirmar o rechazar esta premisa se analizará su interacción, y en el caso de estar frente a una antinomia, se utilizarán criterios interpretativos para resolverla.

\subsection{Interacción normativa}

La Convención de Nueva York determina que no se podrá imponer condiciones más rigurosas a las aplicables a la ejecución de las sentencias arbitrales nacionales; establece los únicos supuestos por lo que se podrá denegar el reconocimiento y la ejecución de un laudo extranjero, y permite que ciertos asuntos procesales se rijan por la ley nacional exceptuando lo relacionado con la carga de la prueba y los documentos que deben ser presentados.

Al remitir el reconocimiento y la ejecución de un laudo extranjero al procedimiento establecido en la ley nacional, siguiendo un criterio de especialidad, la LAM menciona que el laudo se ejecutará del mismo modo que las sentencias de última instancia, y se seguirá la vía de apremio ${ }^{32}$. Si bien previo a la reforma de su artículo 42, este artículo asimilaba al laudo extranjero con el laudo nacional, esto ya no es posible. A pesar de la reforma, al ser el laudo extranjero el instrumento con el que concluye el procedimiento arbitral internacional; en concordancia con el actual artículo 42, y al establecer que el procedimiento arbitral se rige por tratados, convenciones, protocolos y demás actos de derecho internacional suscritos y ratificados por el Ecuador, es apli-

32. LAM, N. 13, Art. 32. 
El Código Orgánico General de Procesos:

puente u obstáculo para la ejecución de un laudo arbitral extranjero en el Ecuador

cable la Convención de Nueva York. En la ley especial de la materia -LAM- no existe un procedimiento específico para este caso por lo que conforme a lo establecido en su artículo 37 es necesario hacer una remisión a otros cuerpos normativos.

En el caso que prime un criterio jerárquico y se opte por acudir directamente al COGEP, es necesario tener presente que a más de las restricciones procesales ya mencionadas, la Convención impone otras limitaciones que se refieren a la imposibilidad de revisar el fondo de la controversia; que las causales para la denegación del reconocimiento y ejecución son exhaustivas; que se las interpreta restrictivamente; y el demandado es quien debe probarlas. Con relación al Código Orgánico General de Procesos hay que enfocarse en el contenido de ciertas normas específicas para compararlo con la Convención de Nueva York.

El artículo 104 establece que para la homologación, la sala competente de la Corte Provincial deberá verificar que:

a) Tengan las formalidades externas necesarias para ser considerados auténticos en el Estado de origen.

La Convención de Nueva York, no habla de formalidades externas sino exige que se presente el documento original de la sentencia arbitral extranjera debidamente autenticado o una copia certificada de ese original. No se considera en todo caso que la imposición de este requisito pueda ser extremadamente gravoso, ya que el solicitante deberá solamente determinar los requisitos formales que debe cumplir un laudo bajo la legislación del lugar donde fue emitido y evidenciar su cumplimiento.

b) La sentencia pasó en autoridad de cosa juzgada conforme con las leyes del país en donde fue dictada y la documentación anexa necesaria está debidamente legalizada.

Según la Convención de Nueva York, de acuerdo al artículo $\mathrm{V}(\mathrm{I})(\mathrm{e})$, la parte contra quien se invoca la solicitud de reconoci- 
miento y ejecución, es quien debe probar que la sentencia no es aun obligatoria conforme la ley que ha sido dictada. Por lo tanto, este requisito impone un exigencia mayor a la prevista por la Convención e invierte la carga de la prueba al solicitante.

c) Que de ser el caso, estén traducidos. Concuerda con la Convención de Nueva York.

d) Que se acredite con las piezas procesales y certificaciones pertinentes que la parte demandada fue legalmente notificada y que se haya asegurado la debida defensa de las partes.

Como se mencionó anteriormente este es el requisito más gravoso y que mayor preocupación acarrea. El artículo V(I)(b) de la Convención de Nueva York establece que la parte contra quien se invoca la solicitud de reconocimiento y ejecución, es quien debe probar que no ha sido debidamente notificada de la designación del árbitro o del procedimiento de arbitraje o no ha podido, por cualquier otra razón, hacer valer sus medios de defensa. Esta causal protege a quien se resiste a la ejecución en razón de que fue impedido de ejercer su derecho de defensa ante el tribunal arbitral.

La causal prevista en la Convención tiene lógica, ya que solamente quien no pudo hacer valer su derecho (hecho negativo), puede alegarlo y debe probarlo. Caso contrario ocurre con lo establecido en este requisito. El derecho a la defensa no supone una sola situación específica, sino es una integralidad conformada por varios derechos, por lo que resultaría sumamente complejo que se demuestre que todos los derechos se respetaron. Lo que en la práctica pudiera ocurrir es que se adjunte todo el proceso arbitral con sus certificaciones pertinentes, lo que conduciría a que el procedimiento sea sumamente oneroso, y se restaría celeridad.

e) Que la solicitud indique el lugar de citación de la persona natural o jurídica contra quien se quiere hacer valer la resolución expedida en el extranjero. 
El Código Orgánico General de Procesos:

puente u obstáculo para la ejecución de un laudo arbitral extranjero en el Ecuador

Este requisito es necesario, y debe constar en la solicitud para el reconocimiento y ejecución del laudo extranjero al ser propio del respeto al debido proceso y derecho a la defensa.

El artículo finaliza mencionando que en el caso de que se solicite el reconocimiento de laudos arbitrales en contra del Estado, por no tratarse de asuntos comerciales, se deberá además demostrar que no contrarían las disposiciones de la Constitución y la ley, y que estén arregladas a los tratados y convenios internacionales vigentes. A falta de tratados y convenios internacionales se cumplirán si constan en el exhorto respectivo, o la ley nacional del país de origen reconoce su eficacia y validez. Para el caso de asuntos no comerciales, la Convención de Nueva York no es aplicable. La Constitución de la República en este aspecto se limita a prohibir al Estado Ecuatoriano participar en arbitrajes internacionales cuya controversia sea de índole comercial, sin embargo, la limitación, como ya se mencionó, no es absoluta.

La primera circunstancia en que la homologación de un laudo en el que sea parte el Estado sea válido, se refiere a la aceptación de todo tipo de arbitrajes regionales -incluso comercialesproducto de un tratado o instrumento internacional entre Estados y ciudadanos en Latinoamérica, excepción que no es contemplada por el Código Orgánico General de Procesos. Esto acarrea dos supuestos. Ante el reconocimiento y ejecución del laudo extranjero proveniente de un arbitraje internacional de índole comercial desarrollado en Latinoamérica, se deberá aplicar la Convención de Nueva York o lo establecido en el instrumento internacional respectivo. Un segundo supuesto se relaciona a laudos producto de un arbitraje internacional en Latinoamérica relativos a controversias no comerciales, en donde se deberá aplicar lo establecido en el Código Orgánico General de Procesos, esto es, demostrar que no se contrarían las disposiciones de la Constitución y la ley, y que esté arreglado a los tratados y convenios internacionales vigentes. 
La segunda excepción se deduce del alcance de la prohibición constitucional de participar en arbitrajes internacionales de índole comercial, dejando abierta la posibilidad de participar en otro tipo de arbitrajes internacionales, como los que surgen de la violación de un tratado internacional. Por ejemplo, al momento de solicitar el reconocimiento de un laudo extranjero producto de una controversia relativa a inversiones bajo el Derecho Internacional Público; en este supuesto se deberá cumplir con lo establecido en el Código Orgánico General de Procesos, es decir, que el procedimiento arbitral y el contenido del laudo ha respetado la legislación ecuatoriana.

\subsection{Criterios para la resolución de antinomias}

Para iniciar se clasificarán los tipos de laudo extranjero en relación a su procedimiento, se identificará la antinomia y se la diferenciará según la clasificación de antinomias propuesta por Ross $^{33}$. Con relación a las contradicciones que se presentan entre las normas analizadas, se las resolverá utilizando el criterio de jerarquía, cronológico y de especialidad ${ }^{34}$.

a) Laudo extranjero producto de un arbitraje comercial internacional entre particulares de países suscriptores de la Convención de Nueva York.

Con relación a los requisitos recogidos en el artículo 104, numeral 2 y 4 del COGEP y lo establecido en los artículos V(I)(b-e) de la Convención de Nueva York, existe una antinomia total-total ya que comparten por completo su ámbito de validez material, personal, temporal y espacial. El aplicar lo establecido en los dos artículos resulta en consecuencias incompatibles.

33. L. Prieto Sanchís, N. 28, p. 133.

34. El criterio de competencia no aplica ya que "el vicio de competencia afecta al acto normativo y no a la norma." Tampoco se utiliza el criterio de prevalencia, ya que se lo utiliza para "superar una antinomia en normas de dos subsistemas normativos y ambas normas son competentes." Ibídem, pp. 137-138. 
El hecho de que el artículo del COGEP conste en una norma inferior a la Convención de Nueva York, produce una antinomia de diverso nivel jerárquico, lo que significaría que "la norma inferior no es válida, no simplemente que no debe aplicarse al caso, sino que no debería existir o debería dejar de existir. ${ }^{35 "}$ En el ordenamiento jurídico ecuatoriano existe un procedimiento especial para declarar la invalidez de la norma, sin embargo, incluso prescindiendo de aquel procedimiento el juez no debería aplicarla, dado que a pesar de ser una norma aparentemente válida resultaría ser ineficaz. El criterio cronológico no procede a pesar de que el COGEP haya sido promulgado de manera posterior a la Convención de Nueva York; en este caso prevalece el criterio jerárquico y al tratarse de un instrumento internacional, la Convención no pierde su vigencia. Con relación al criterio de especialidad, la Convención de Nueva York es la que prima al ser norma especial y exclusiva para el reconocimiento y ejecución de un laudo extranjero.

b) Laudo extranjero producto de un arbitraje comercial internacional desarrollado por instancias arbitrales regionales (Latinoamérica) en los que haya sido parte el Estado ecuatoriano.

La Constitución de la República permite el desarrollo de arbitrajes internacionales regionales de índole comercial que involucre al Estado, solo si son producto de un tratado o instrumento internacional entre Estados y ciudadanos en Latinoamérica. El COGEP, parte de una premisa absoluta e incurre en el error de que un laudo extranjero en contra del Estado no pueda ser índole comercial. En este caso existe un contradicción entre permiso positivo establecido en la Constitución y lo que el Código considera como prohibido. En la clasificación de Ross, podría suponerse de manera forzada que existe una antinomia parcial-parcial, ya que lo establecido por el Código presenta un ámbito de validez suplementario para los casos en general, y solo para el presente supuesto, que resulta ser una excepción, entraría en conflicto. Al ser 
forzado este supuesto, preferiblemente "puede hablarse de una laguna técnica o de eficacia para referirse a la ausencia de una norma (generalmente inferior) necesaria para satisfacer o hacer efectivo lo establecido en otra norma (generalmente superior). ${ }^{35 \prime}$ De esta forma superada la laguna técnica, para este caso se aplicaría Código Orgánico General de Procesos con las limitaciones impuestas por la Convención de Nueva York.

c) Laudo extranjero producto de un arbitraje internacional no comercial desarrollado por instancias arbitrales regionales (Latinoamérica) en los que haya estado presente el Estado.

Se aplica únicamente el Código Orgánico General de Procesos.

d) Laudo extranjero producto de un arbitraje internacional no comercial.

Se aplica únicamente el Código Orgánico General de Procesos.

\section{Conclusiones}

De la relación que existe entre los cuerpos normativos analizados, se constatan las siguientes conclusiones:

a) Previo a la promulgación del Código Orgánico General de Procesos, el artículo 42 de la Ley de Arbitraje y Mediación otorgaba los mismos efectos de un laudo nacional a uno extranjero. Este hecho suponía que no era necesario el solicitar el reconocimiento de un laudo extranjero, ya que debía ejecutarse como un laudo nacional mediante la vía de apremio. Con la reforma el solicitar el reconocimiento de un laudo extranjero es necesario para su ejecución. 
b) Si bien uno de los fines del COGEP es el superar ciertas deficiencias del Código de Procedimiento civil, parece ser que el puente que se busca implementar para el procedimiento de reconocimiento y ejecución de un laudo extranjero, a la luz de la Convención de Nueva York lo es solo en forma aparente.

c) El fin último de un puente es ser un conector que facilita la movilidad, sin embargo, previa a su construcción se debe tener en cuenta quienes lo utilizarán para ajustarse a sus exigencias y determinar así los materiales correctos. Desde el momento en el que se incluyó en el COGEP un capítulo relacionado con sentencias, laudos arbitrales y actas de mediación expedidos en el extranjero, se incurrió en el error de no considerar la naturaleza jurídica de cada instrumento; esto genera la primera deficiencia que denota una redacción que no siempre utiliza los términos adecuados para la materia.

d) Como se expuso a lo largo del presente trabajo, algunos de los requisitos exigidos por el COGEP incumplen con lo que dispone la Convención de Nueva York por ser más gravosos y no otorgar un mismo tratamiento a los laudos nacionales e internacionales.

e) Hasta el momento, el esquema normativo del COGEP no ha sido utilizado, sin embargo, de exigirse su aplicación puede ocasionarse que el Estado sea responsable por el incumplimiento de un tratado internacional. Alternativamente, frente al problema jurídico, un juez puede no exigir la aplicación de los requisitos que vulneran lo establecido en la Convención en base del principio de jerarquía normativa dispuesto en el artículo 425 de la Constitución de la República del Ecuador.

f) Finalmente el camino para el reconocimiento y la ejecución de un laudo extranjero en el Ecuador no tiene todavía un procedimiento claro. A pesar del trabajo interpretativo realizado en el presente ensayo, se constata que es necesario la implementación de un procedimiento expedito que realmente sirva como un vínculo para que se cumpla con lo establecido en instrumentos internacionales, y en último término, sea concordante con los fines del arbitraje. 